\title{
Continued breakdown of the blood aqueous barrier following cataract surgery
}

\begin{abstract}
Following routine extracapsular cataract and posterior chamber implant surgery, recovery of the blood aqueous barrier (BAB) was quantified by sequential anterior chamber fluorophotometry. This was correlated with surgical details and postoperative findings to ascertain those factors which were related to excessive damage of the BAB immediately after surgery and to failure to recover a normal BAB by 3 months postoperatively. A cohort of 84 patients was followed. In the early postoperative period excessive levels of damage to the BAB were related to iris damage $(p<0.01)$ and diabetes mellitus $(p<0 \cdot 01)$. By 3 months, $79 \%$ of the eyes had recovered normal BABs and $21 \%$ (18 eyes) had persisting excessive fluorescence which correlated with an abnormal pupil shape $(p<0.02)$ and the development of posterior synechiae $(\mathbf{p}<\mathbf{0 . 0 0 1})$.

(Brf Ophthalmol 1992; 76: 453-456)
\end{abstract}

Extracapsular cataract surgery with insertion of posterior chamber intraocular lenses causes breakdown of the blood aqueous barrier (BAB) which usually recovers within 3 months of uncomplicated surgery ${ }^{1-3}$ Failure to recover the BAB may be associated with a need for continued medication and the potential development of problems such as posterior capsule thickening, cystoid macular oedema, or continuing endothelial cell loss leading to future visual problems. Anterior chamber fluorophotometry measures the degree of $\mathrm{BAB}$ breakdown by quantifying the amount of fluorescence in the anterior chamber (AC) following intravenous injection of sodium fluorescein.

In this series 130 patients undergoing routine extracapsular surgery with posterior chamber implants were studied by sequential anterior chamber fluorophotometry during the first 3 months following surgery. The fluorophotometry results were correlated with the clinical findings. The aim was to find out which operative and clinical features were related to excessive damage to the $B A B$ immediately after surgery or failure to recover the $\mathrm{BAB}$ by 3 months postoperatively.

Medical Eye Unit, St
Thomas' Hospital,
London
V M G Ferguson
D J Spalton
Correspondence to:
Mr D J Spalton FRCP, FRCS,
Medical Eye Unit, St Thomas'
Hospital, London SE1 7EH.
Accepted for publication
23 December 1991

\section{Method}

Ethical approval was obtained from the West Lambeth Health Authority for the study which took place between December 1987 and June 1989. The patients had no severe cardiovascular or respiratory disease or known allergy and were willing to cooperate with intravenous fluorophotometry, but were otherwise unselected. Extracapsular cataract surgery with posterior chamber implants was performed on 130 patients (130 eyes). The surgical details recorded were the use of preoperative topical indomethacin, the experience of the surgeon, the type of section (limbal or corneal), the fixation of the implant (either in the ciliary sulcus or the capsular bag) and whether a subconjunctival injection of steroid was given.

Patients were studied within 7 days of surgery and at 1,2, and 3 months postoperatively. At each visit the clinical findings were recorded and AC fluorophotometry was performed. Intravenous fluorescein sodium $(20 \% \mathrm{w} / \mathrm{v}, 14 \mathrm{mg} / \mathrm{kg})$ was given and fundus fluorescein angiography was performed; 60 minutes later fluorophotometry scans of the anterior chamber were recorded using a 'Fluorotron Master' (Coherent Radiation) fluorophotometer as previously described' so that four AC fluorescence readings made at 4 week intervals were produced for each eye.

The anterior segment was examined by biomicroscopy and the degree of conjunctival injection, anterior chamber cells, and flare were graded on a scale of 0 to 3 . The shape of the pupil, whether round, irregular, or eccentric was recorded. Transillumination of the iris was quantified by retroillumination through the pupil; the iris was divided into eight sectors and the loss of iris pigment epithelium in any sector was recorded immediately after surgery and again at 3 months. The number of sectors with loss of pigment epithelium immediately postoperatively was taken as being surgically induced and progression of these or an increase in affected sectors at 3 months was taken to indicate iris chafing by the implant. Similarly the development of posterior synechiae (PS) at 3 months was graded according to the number of sectors of the iris involved with PS. The centricity of the implant, whether central or eccentric, was noted at 3 months. The best corrected visual acuity at each visit and any opacity of the posterior capsule were also recorded.

\section{Results}

A total of 130 patients started and 84 completed the study; 25 patients failed to attend for all four measurements and another 13 declined to complete the study because of nausea caused by intravenous fluorescein. Eight patients were excluded; five because of preoperative uveitis, two highly myopic patients with no implant and one with a dislocated implant which had to be repositioned. There were 31 males, 53 females, (68 Caucasian, nine Negro, seven Asian), aged 43 to 83 years (mean age $67 \cdot 7$ years, SD 9.0).

The normal AC fluorescence to be expected in the eyes of patients of this age was established in 
Figure 1 Anterior chamber fluorescence in $\mathrm{ng} / \mathrm{ml}$ immediately after surgery (y axis) plotted against anterio chamber $(A C)$ fluorescence at 3 months postoperatively ( $x$ axis) in a total of 84 eyes. $A, B, C$ and $D$ are the four groups where $A$ and $D$ had relatively low amounts of $A C$ fluorescence in the first week after surgery and $B$ and $C$ had excessive $A C$ fluorescence. At 3 months groups $A$ and $B(78 \cdot 6 \%$ of all the eyes) had recovered normal $B A B$ s whereas groups $C$ and $D(21 \%$ of all the eyes) had abnormally high AC fluorescence representing a continued breakdown of the blood aqueous barrier.

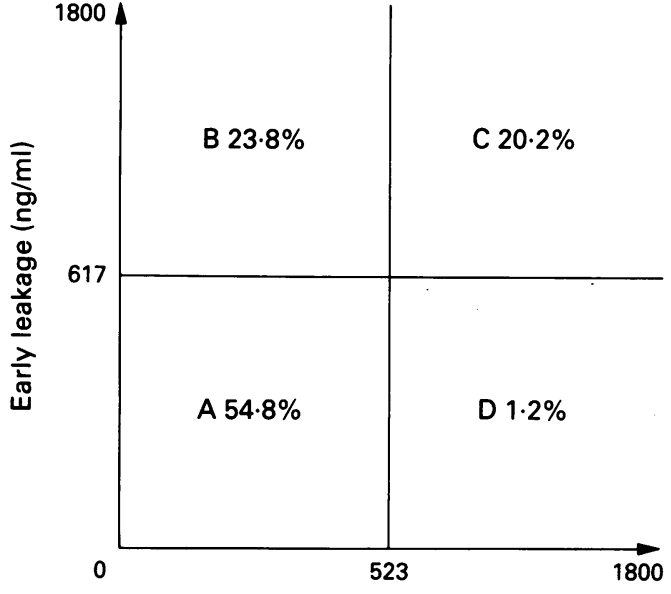

Late leakage (ng/ml)

a separate study by measuring the AC fluorescence in both eyes of nine healthy volunteers (mean age 62) on two separate occasions. The normal level was 338 plus $186 \mathrm{ng} / \mathrm{ml}$ (mean with $2 \mathrm{SD})$.

Four groups of eyes were identified postoperatively (Fig 1): group A had low AC fluorescence immediately postoperatively and a normal BAB at 3 months (46 out of 84 eyes, $54.8 \%$ ), group B had high AC fluorescence immediately postoperatively but recovered a normal BAB at 3 months (20 eyes, $23 \cdot 8 \%$ ), group $C$ had high AC fluorescence immediately postoperatively and failed to recover a normal BAB at 3 months (17 eyes, $20 \cdot 2 \%$ ) and group D started with low AC fluorescence immediately postoperatively but had an abnormal BAB at 3 months ( 1 eye, $1 \cdot 2 \%$ ). Figure 2 shows the range of AC fluorescence values measured within 7 days of surgery. Most eyes ( 37 out of 84 ) had levels of fluorescence comparable to unoperated eyes, that is within $338 \mathrm{ng} / \mathrm{ml}$ plus $2 \mathrm{SD}$. Immediately after surgery all the eyes were expected to have some degree of damage to the BAB, but $23 \cdot 8 \%$ had excessively high levels of leakage. An arbitrary level of $617 \mathrm{ng} / \mathrm{ml}$ was taken as the threshold for abnormally high fluorescence in the early postoperative period. This represents the mean AC fluorescence for increment represents the unoperated eyes plus multiples of the standard deviation.

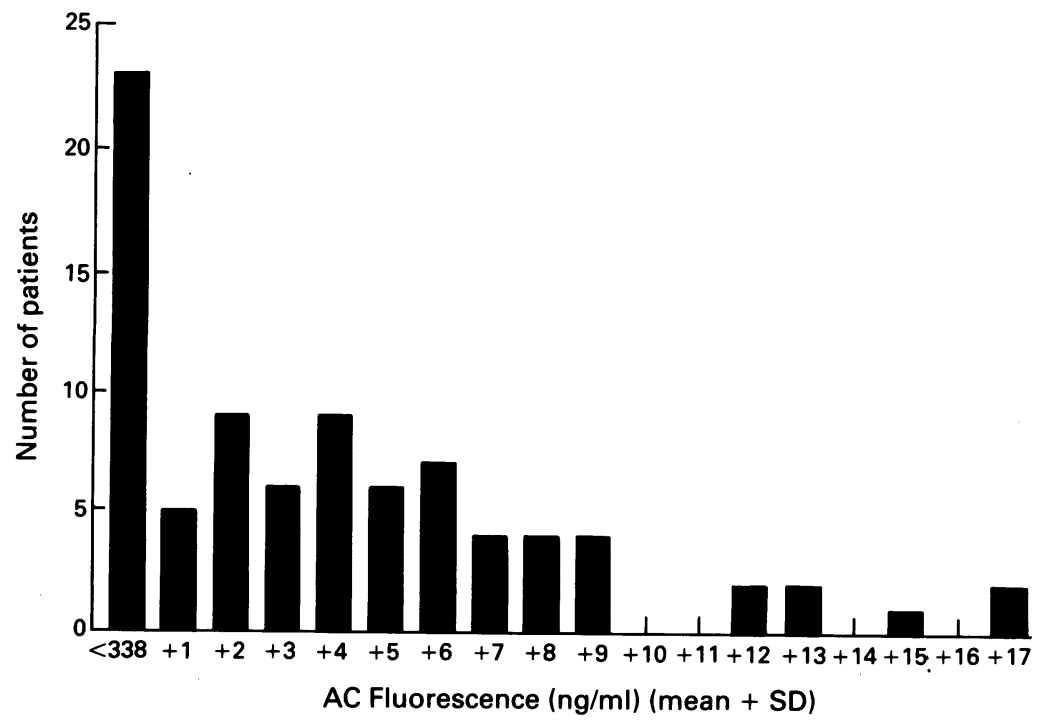

normal unoperated eyes ( $338 \mathrm{ng} / \mathrm{ml}$ plus $3 \mathrm{SD}$ ). At 3 months after surgery AC fluorescence of less than $523 \mathrm{ng} / \mathrm{ml}$ (mean $+2 \mathrm{SD}$ ) represented recovery of a normal BAB.

Immediately postoperatively $56 \%$ of all eyes (47 out of 84) were in the 'low leakage' group with AC fluorescence less than $617 \mathrm{ng} / \mathrm{ml}$ (groups A+D), and 44\% had fluorescence greater than $617 \mathrm{ng} / \mathrm{ml}$ and formed the 'high leakage' group (groups $\mathrm{B}+\mathrm{C}$ ). At 3 months postoperatively $78.6 \%$ of all eyes had recovered a normal BAB (groups A+B) but $21 \cdot 4 \%$ had continued breakdown of the $\mathrm{BAB}$ with fluorescence greater than $523 \mathrm{ng} / \mathrm{ml}$ (groups C+D); $54 \%$ of those with very high fluorescence immediately after surgery subsequently recovered a normal $\mathrm{BAB}$ by 3 months ( 20 eyes out of 37 in groups $B+C$ ).

The surgical and clinical findings were compared with the AC fluorescence; firstly in the immediate postoperative period and secondly at 3 months so that the factors related to excessive damage to the BAB immediately after surgery (Table 1) and to continued breakdown of the BAB (Table 2) could be elucidated. The statistical significance of the differences between the groups of eyes was shown using the $\chi^{2}$ test.

In the early postoperative period the significant factors for high leakage was iris damage $(p<0.01)$ and the presence of diabetes $(p<0.01)$. This raised the possibility that the diabetic patients may be the ones with excessive iris damage so a further analysis was made comparing the high leakage and low leakage eyes again but excluding the 10 diabetic patients in the study. The findings were similar with a statistically significant correlation between high leakage and iris damage $(p<0.05)$. At 3 months the factors related to continued breakdown of the $\mathrm{BAB}$ were an abnormal pupil shape $(\mathrm{p}<0.02)$ and the presence of posterior synechiae $(\mathrm{p}<0.001)$ (Table 2). The posterior synechiae were all located in the mid or peripheral iris rather than at the pupil margin.

\section{Discussion}

Anterior segment fluorophotometry demonstrates the degree of damage to the $B A B$ after routine cataract surgery. Although fluorophotometry has been used extensively to study the effect of cataract surgery on the eye we are not aware of any other study where patients have been studied postoperatively as a sequential cohort. Our results were analysed in two groups: those with high levels of AC fluorescence immediately postoperatively and those failing to recover their BABs by 3 months. In this study we have shown which clinical and surgical factors are related to breakdown of the BAB in the early and late postoperative period.

HIGH FLUORESCENCE IMMEDIATELY POSTOPERATIVELY (TABLE 1)

The presence of diabetes mellitus was related to excessive damage to the BAB immediately after surgery $(p<0.001)$. Diabetic eyes appear to have more permeable iris vessels than normal eyes and are likely to be more susceptible to surgical trauma. Endothelial cells and basement mem- 
brane are altered in the iris vessels of diabetic eyes $^{45}$ and diabetic eyes with retinopathy have more protein in the aqueous and this increases with the severity of the retinopathy. ${ }^{6}$ From the clinical point of view Cunliffe et $a l^{7}$ found that diabetic patients had a higher incidence of inflammation and macular oedema postimplantation in comparison to age matched normal eyes.

The second factor correlating with excessive damage to the $\mathrm{BAB}$ was trauma to the iris $(\mathrm{p}<0 \cdot 01)$, shown by changes in the pupillary appearance due to pupillary sphincter damage, iris tucking (caused by the implant, residual capsule fragment or capture of iris in the section) or iris trauma from surgical handling. It is not surprising that iris trauma is so important when

Table 1 Comparison of patients with normal (Group $A+D)$ and excessive levels of damage to the $B A B($ Group $C+B)$ immediately after surgery.

\begin{tabular}{|c|c|c|c|}
\hline Clinical features & $\begin{array}{l}\% \text { of patients } \\
\text { Group } A+D\end{array}$ & $\begin{array}{l}\text { th feature } \\
\text { Group } B+C\end{array}$ & $p$ \\
\hline $\begin{array}{l}\text { Topical preoperative indomethacin } \\
\text { Experienced surgeon } \\
\text { Junior surgeon } \\
\text { Limbal section } \\
\text { Corneal section }\end{array}$ & $\begin{array}{l}21 \cdot 3 \% \\
63 \cdot 8 \\
36 \cdot 2 \\
27 \cdot 7 \\
72 \cdot 3\end{array}$ & $\begin{array}{l}18 \cdot 9 \\
78 \cdot 4 \\
21 \cdot 6 \\
35 \cdot 1 \\
64 \cdot 9\end{array}$ & $\begin{array}{l}>0.2 \\
>0.1 \\
>0.1 \\
>0.2 \\
>0.2\end{array}$ \\
\hline $\begin{array}{l}\text { IOL fixation } \\
\text { sulcus } \\
\text { bag } \\
\text { Subconjunctival steroid at operation } \\
\text { Injected conjunctiva in first post-op week } \\
\text { AC flare }(2+) \text { in first week } \\
\text { AC cells }(2+) \text { in first week } \\
\text { Topical steroid continued }>6 / 52 \text { postoperatively } \\
\text { Postoperative pupil }\end{array}$ & $\begin{array}{l}53 \cdot 2 \\
46 \cdot 8 \\
14 \cdot 9 \\
40 \cdot 4 \\
19 \cdot 1 \\
21 \cdot 3 \\
37 \cdot 0 \%\end{array}$ & $\begin{array}{l}59 \cdot 5 \\
40 \cdot 5 \\
21 \cdot 6 \\
51 \cdot 4 \\
8 \cdot 1 \\
35 \cdot 1 \\
40 \cdot 5 \%\end{array}$ & $\begin{array}{l}>0 \cdot 2 \\
>0 \cdot 2 \\
>0 \cdot 2 \\
>0 \cdot 2 \\
>0 \cdot 1 \\
>0 \cdot 1 \\
>0 \cdot 2\end{array}$ \\
\hline $\begin{array}{l}\text { round } \\
\text { oval } \\
\text { Postoperative iris transillumination } \\
\text { Hypertension } \\
\text { Diabetes } \\
\text { Development of posterior synechiae }(>2+) \text { at }\end{array}$ & $\begin{array}{r}93 \cdot 6 \\
6.4 \\
8.5 \\
19 \cdot 1 \\
0\end{array}$ & $\begin{array}{l}73 \cdot 0 \\
27 \cdot 0 \\
13 \cdot 5 \\
29 \cdot 7 \\
24 \cdot 3\end{array}$ & $\begin{array}{l}<0.01^{\star} \\
<0.01^{\star} \\
>0.2 \\
>0.2 \\
<0.001^{\star}\end{array}$ \\
\hline $\begin{array}{l}3 \text { months } \\
\text { Visual acuity worse than } 6 / 12 \text { at } 3 \text { months } \\
\text { Normal BAB at } 3 \text { months }\end{array}$ & $\begin{array}{l}6 \cdot 4 \\
4 \cdot 4 \% \\
97 \cdot 8 \%\end{array}$ & $\begin{array}{l}21 \cdot 6 \\
5 \cdot 7 \% \\
54 \%\end{array}$ & $\begin{array}{l}<0.04^{\star} \\
>0.2 \\
<0.0001^{\star}\end{array}$ \\
\hline
\end{tabular}

Percentages apply to the number of patients in each group to which that particular feature applied. ( ${ }^{\star}=$ statistically significant with $\chi^{2}$ analysis).

Table 2 Comparison of patients with normal recovery (groups $A+B$ ) to those with continued breakdown of the BAB at 3 months (Groups $C+D$ )

\begin{tabular}{|c|c|c|c|}
\hline Clinical features & $\begin{array}{l}\% \text { of patients } 2 \\
\text { Group } A+B\end{array}$ & $\begin{array}{l}\text { th feature } \\
\text { Group } C+D\end{array}$ & $p$ \\
\hline $\begin{array}{l}\text { Topical preoperative indomethacin } \\
\text { Experienced surgeon } \\
\text { Junior surgeon } \\
\text { Limbal section } \\
\text { Corneal section } \\
\text { IOL fixation }\end{array}$ & $\begin{array}{l}21 \cdot 2 \% \\
70 \cdot 2 \\
28 \cdot 8 \\
31 \cdot 8 \\
66 \cdot 2\end{array}$ & $\begin{array}{l}16 \cdot 7 \\
66 \cdot 7 \\
33 \cdot 3 \\
27 \cdot 8 \\
72 \cdot 2\end{array}$ & $\begin{array}{l}>0.2 \\
>0.2 \\
>0.2 \\
>0.2 \\
>0.2\end{array}$ \\
\hline $\begin{array}{l}\text { sulcus } \\
\text { bag } \\
\text { Subconjunctival steroid at operation } \\
\text { Injected conjunctiva in first postoperative week } \\
\text { AC flare }(2+) \text { in first week } \\
\text { AC cells }(2+) \text { in first week } \\
\text { IOL position at } 3 \text { months }\end{array}$ & $\begin{array}{l}56 \cdot 1 \\
43 \cdot 9 \\
13 \cdot 6 \\
45 \cdot 5 \\
16 \cdot 7 \\
24 \cdot 2\end{array}$ & $\begin{array}{r}55 \cdot 6 \\
44 \cdot 4 \\
33 \cdot 3 \\
33 \cdot 3 \\
5 \cdot 6 \\
38 \cdot 9\end{array}$ & $\begin{array}{l}>0.2 \\
>0.2 \\
>0.06 \\
>0.2 \\
>0.2 \\
>0.2\end{array}$ \\
\hline $\begin{array}{l}\text { central } \\
\text { eccentric } \\
\text { Pupil appearance at } 3 \text { months }\end{array}$ & $\begin{array}{l}69 \cdot 7 \\
30 \cdot 3\end{array}$ & $\begin{array}{l}77 \cdot 8 \\
22 \cdot 2\end{array}$ & $\begin{array}{l}>0.2 \\
>0.2\end{array}$ \\
\hline $\begin{array}{l}\text { Pupil appearance at } 3 \text { months } \\
\text { round } \\
\text { oval } \\
\text { Increased iris transillumination }>2+ \\
\text { Presence of posterior synechiae }(>2+) \text { at } 3 \text { months } \\
\text { Significant posterior capsule opacity at } 3 \text { months } \\
\text { Topical steroid continued }>6 / 52 \text { postoperatively } \\
\text { Visual acuity worse than } 6 / 12 \text { at } 3 \text { months }\end{array}$ & $\begin{array}{r}89 \cdot 4 \\
10 \cdot 6 \\
12 \cdot 1 \\
6 \cdot 1 \\
4 \cdot 5 \\
39 \cdot 4\end{array}$ & $\begin{array}{l}66 \cdot 7 \\
38 \cdot 9 \\
27 \cdot 8 \\
38 \cdot 9 \\
0 \\
38 \cdot 9\end{array}$ & $\begin{array}{l}<0.02^{\star} \\
<0.02^{\star} \\
>0 \cdot 1 \\
<0.001^{\star} \\
>0 \cdot 2 \\
>0 \cdot 2\end{array}$ \\
\hline $\begin{array}{l}\text { (excl DM, SMD) } \\
\text { Diabetes } \\
\text { Hypertension } \\
\text { Angiographic CMO at } 3 \text { months excluding diabetic }\end{array}$ & $\begin{array}{r}4 \cdot 5 \\
9 \cdot 1 \\
21 \cdot 2\end{array}$ & $\begin{array}{r}5 \cdot 6 \\
16 \cdot 7 \\
33 \cdot 3\end{array}$ & $\begin{array}{l}>0.2 \\
>0.2 \\
>0.2\end{array}$ \\
\hline or age related maculopathy (grade $2+$ or more) & $6 \cdot 3$ & 0 & $<0 \cdot 2$ \\
\hline
\end{tabular}

Percentages apply to the number of patients in each group to which that particular feature applied. $\left({ }^{\star}=\right.$ statistically significant with $\chi^{2}$ analysis.) one considers that this is a highly vascular tissue which is easily damaged if handled during the operation. By excluding the 10 diabetic patients and repeating the comparison between high and low leakage groups, the significant correlation between iris damage and breakdown of the $B A B$ barrier independent of diabetes was confirmed $(\mathrm{p}<0.05)$.

Other surgical factors such as the experience of the surgeon, a vascularised limbal or a nonvascularised corneal section, the fixation of the implant or defects in the iris pigment epithelium did not appear to influence the degree of damage to the BAB immediately postoperatively. Also there was no evidence that preoperative treatment with topical indomethacin $(p=0.6)$ or perioperative injection of subconjunctival steroids $(p=0.4)$ influenced the degree of damage to the $\mathrm{BAB}$ in this early postoperative period. Surprisingly there do not appear to be any studies as far as we are aware on the advantages or otherwise of subconjunctival steroids given at the time of surgery. The effect of indomethacin on the $\mathrm{BAB}$ has been extensively studied in terms of its effect on prostaglandins in the aqueous, ${ }^{8}$ its effect on the incidence of cystoid macular oedema, ${ }^{9-11}$ its effect on the $\mathrm{BAB}^{12}$ and the benefit of maintaining mydriasis during surgery..$^{13}$ Indomethacin prevents surgically induced miosis which makes surgery technically easier with less potential for excessive manipulation of the iris and it may be that the majority of the beneficial effects of prostaglandin inhibitors are mediated through this mechanism, particularly as the effects are of relatively short duration. Using pre- and postoperative topical indomethacin Miyake ${ }^{15}$ showed reduced AC fluorophotometry measurements in the first 4 weeks postoperatively and Sanders $e t a l^{2}$ demonstrated recovery of the $\mathrm{BAB}$ by 5 weeks postoperatively in treated eyes compared to untreated eyes which did not show complete recovery of the $\mathrm{BAB}$ until 3 months after uncomplicated surgery.

Of all the eyes with high levels of leakage immediately after surgery (group B+C) $46 \%$ of them failed to recover their BAB by 3 months. Some of these would probably recover fully with a longer follow up. This initial high leakage group (group B $+\mathrm{C}$ ) were not given more topical steroids than the low leakage group (group A+ D), $p=0 \cdot 8$. They had an increased tendency to formation of posterior synechiae at 3 months $(p<0.05)$ but their final visual acuities were not different from the low leakage group, $\mathrm{p}=0 \cdot 8$.

HIGH AC FLUORESCENCE AT 3 MONTHS (TABLE 2) Our findings show that at 3 months after surgery $78.6 \%$ of all eyes in the study had recovered a normal BAB. Sanders and Kraff ${ }^{2}$ also showed that the $\mathrm{BAB}$ took 3 months to recover following uncomplicated extracapsular and implant surgery, although only $60(25 \%)$ of their patients completed their 3 month study. We found that persisting breakdown of the BAB at 3 months was associated with an abnormal pupil shape $(p<0.02)$ and the development of posterior synechiae $(p<0.001)$. These two factors may be related because posterior synechiae may cause an abnormal shape. The development of 
posterior synechiae in the high leakage group (C+D) must indicate continuing inflammation as a result of mechanical, immunological, or possibly bacteriological factors. Overall $26 \%$ of the eyes developed posterior synechiae in one or more sectors and it is interesting that this percentage compares closely to a post mortem study ${ }^{16} 17$ where the authors found histological evidence of inflammatory changes in $31 \%$ of eyes with posterior chamber implants. We think that this suggests that the in vivo results from fluorophotometry showing failure to re-establish the BAB by 3 months are reflected by clinical and pathological evidence of continuing inflammatory processes in the eye.

Factors such as the type of section or the position of the implant in the ciliary sulcus or capsular bag were not significantly associated with breakdown of the BAB at 3 months. This is supported by other studies ${ }^{13} 1519$ which show that in the early recovery of the BAB after cataract surgery the presence or absence of an implant or its fixation in the bag or sulcus has no significant effect on the $\mathrm{BAB}$. This would indicate that the major factors influencing the degree of damage to the $B A B$ in the early postoperative period are related mainly to surgical techniques. Fixation of the implant is important in long term studies. Miyake ${ }^{3}$ looked at fixation of the implant at least 12 months after surgery and found that eyes within the bag placement of the implant had less damage to the BAB than eyes with the implant in the ciliary sulcus, although, with longer follow-up to 3 years, there was no difference between eyes with sulcus or bag fixated posterior chamber implants or even any difference between pseudophakic and aphakic eyes.

One might have expected those eyes in our study who developed an increase in iris pigment loss following surgery ( 15 eyes) to show increased damage to the BAB. This did not happen and the reason for this is probably that the iris pigment epithelium is avascular and may initially cushion the iris stroma from chaffing. We would anticipate that if chaffing continued those eyes would eventually show damage to the BAB. There was no evidence in this study of an association of posterior capsule opacity with changes in the $B A B$ in the first 3 months after operation which was to be expected as significant posterior capsule opacity is likely to take several months to develop and would occur after the study had been completed. There was an increased incidence of angiographic cystoid macular oedema (CMO) in the eyes with high AC fluorescence at 3 months $(p<0.05)$ but when the four eyes with senile macular degeneration or diabetic maculopathy were excluded there was no significant difference between the groups. Our results show an overall incidence of persisting angiographic CMO in 5\% (four out of 80 ) of patients at 3 months. This compares with $6.8 \%$ of eyes with $2+$ or more angiographic $\mathrm{CMO}$ in the study by Wright et al. ${ }^{20}$

The results of this sequential study show that breakdown of the BAB immediately after surgery is closely related to the amount of iris trauma during surgery. The degree of iris trauma was independent of diabetes which was also a factor related to increased anterior chamber fluorescence. This emphasises the need for meticulous surgical technique particularly with diabetic patients. At 3 months postoperatively the major factors also appear to be associated with structural changes in the iris and the development of posterior synechiae, probably reflecting continuing inflammatory processes in the eye. Cataract surgery is at present undergoing a major period of change from planned extracapsular surgery to capsulorrhexis and small incision phacoemulsification surgery. A major advantage of this latter style of surgery is potential avoidance of any uveal contact either during surgery or postoperatively and it will be interesting to see if this is reflected by lower degrees of damage to the $\mathrm{BAB}$ postoperatively.

This work was supported by the Iris Fund for Prevention of Blindness.

1 Ferguson VMG, Spalton DJ. Recovery of the blood-aqueous barrier after cataract surgery. Br $\mathcal{F}$ Ophthalmol 1991; 75: 106-10.

2 Sanders DR, Kraff MC, Lieberman HL, et al. Breakdown and re-establishment of blood-aqueous barrier with implant surgery. Arch Ophthalmol 1982; 100: 588-90.

3 Miyake K, Asakura M, Kobayashi H. Effect of intraocular lens fixation on the blood-aqueous barrier $A m \mathcal{F}$ Ophthalmol 1984; 98: 451-5.

4 Kojima K, Niimi K, Hasegawa Y, et al. Electron microscopic studies on the small vessels of the iris in human diabetes mellitus. Acta Soc Ophthalmol fpn 1973; 77: 485-93.

5 Taniguchi T, Sameshima M. Fine structure of small blood vessels in the iris of human diabetics. Acta Soc Ophthalmol Fpn 1971; 75: 1685-97.

6 Oshika T, Kato S, Funatsu H. Quantitative assessment of aqueous flare intensity in diabetes. Graefes Arch Clin Exp Ophthalmol 1989; 227: 518-20.

7 Cunliffe IA, Flanagan DW, George NDL, et al. Extracapsula cataract surgery with lens implantation in diabetics with and without proliferative retinopathy $B r 7$ Ophthalmol 1991; 75 : 9-12.

8 Miyake $\mathrm{K}$. Indomethacin in the treatment of postoperative cystoid macular edema. Surv Ophthalmol 1984; 28 (suppl): 554-68

9 Miyake K, Sakamura S, Miura H. Long term follow-up study on prevention of aphakic cystoid macular oedema by topical indomethacin. Brf Ophthalmol 1980; 64: 324-8.

10 Yannuzzi LA, Landau AN, Turtz AI. Incidence of aphakic cystoid macular edema with the use of topical indomethacin. Ophthalmology 1988; 88: 947-54.

11 Kraff MC, Sanders DR, Jampol LM, et al. Prophylaxis of pseudophakic cystoid macular edema with topical indopseudophakic cystoid macular edema with
methacin. Ophthalmology 1982; 89: 885-90.

12 Sanders DR, Kraff $M$. Steroidal and non-steroidal antiinflammatory agents. Effect on postsurgical inflammation and blood-aqueous humor barrier breakdown. Arch Ophthalmol 1984; 102: 1453-6.

13 Neilsen PJ, Gregersen P, Mortensen KK, et al. The effect of indomethacin $1 \%$ ophthalmic suspension in preventing surgically induced miosis at extracapsular cataract surgery. Acta Ophthalmol 1987; 65 (suppl 182): 115-8.

14 Keates RH, McGowan KA. The effect of topical indomethacin ophthalmic solution in maintaining mydriasis during cataract surgery. Ann Ophthalmol 1984; 16: 1116-21.

15 -Miyake K. Fluorophotometric evaluation of the blood-ocular barrier function following cataract surgery and intraocular lens implantation. $\mathcal{F}$ Cataract Refract Surg 1988; 14: 560-8.

16 McDonnell PJ, Green WR, Champion R. Pathological changes in pseudophakia. Sem Ophthalmol 1986; 1: 80-103.

17 McDonnell PJ, Champion R, Green WR. Location and composition of haptics of posterior chamber intraocula lenses. Histopathologic study of postmortem eyes. Ophthalmology 1987; 94: 136-42.

18 Sawa M, Sakanishi Y, Okuno Y, Shimizu H. Posterior chamber lens implantation and anterior segment barrier function: a fluorophotometric study. $\mathcal{F p n ~} \mathcal{F}$ Ophthalmol 1988; 32: 297-303.

19 Menerath JM, Coulangeon LM, Al-Odeh A. Evaluation fluorophotometrique des barrieres hemato-oculaires dans la fluorophotometrique des barrieres hemato-oculaires dan

20 Wright PL, Wilkinson CP, Balyeat HD, et al. Angiographic cystoid macular edema after posterior chamber lens implantation. Arch Opthalmol 1988; 106: 740-4. 